\title{
PLANEJAMENTO FAMILIAR: AUTONOMIA OU ENCARGO FEMININO?
}

\author{
Maria Helena Camargos Moreira \\ José Newton Garcia de Araújo\#
}

\begin{abstract}
RESUMO. Este trabalho está baseado em uma pesquisa desenvolvida numa unidade de saúde pública da prefeitura de Belo Horizonte, Minas Gerais. Ele visou acompanhar a implementação de grupos de planejamento familiar junto a uma população de baixa renda. Observou-se uma presença quase absoluta de mulheres, nesses grupos. Entrevistas com essas mulheres e com os profissionais daquele programa mostraram que a prevalência feminina nos grupos estava relacionada a atitudes ou valores culturais, bem como às condições de funcionamento da unidade. Isso, no entanto, não significava a autonomia das mulheres, na escolha do método contraceptivo, pois elas permaneciam subalternas aos parceiros sexuais. Pesquisas documentais também revelaram alguns equívocos e lacunas nas políticas públicas, tanto no texto do programa em questão quanto no modo de sua implantação, o que sugere a ambigüidade das práticas ligadas à construção dos direitos reprodutivos no Brasil.
\end{abstract}

Palavras-chave: planejamento familiar, gênero, direitos reprodutivos.

\section{FAMILY PLANNING: FEMALE AUTONOMY OR BURDEN}

\begin{abstract}
This paper is based on a research developed in a municipal public health unit of Belo Horizonte, Minas Gerais (Brazil). The objective was to follow the implantation of family planning groups, involving a low-income population. It was observed that women were the great majority in the groups. Some interviews with the women and professionals of the referred program have shown that the prevalence of female individuals in the groups was related to cultural values, as well as to the management of that health unit. However, it did not mean the women had the autonomy to choose their contraceptive method. They remained submitted to their sexual partner's choice. The research also showed some mistakes and gaps in the public policies, not only in its proposal text, but also in the procedures of its implantation. It suggests an ambiguity among the practices linked to the construction of birth control rights in Brazil.
\end{abstract}

Key words: family planning, gender, birth control rights.

\section{O PLANEJAMENTO FAMILIAR TEM 'ROSTO DE MULHER"}

(...) Aos poucos, elas vão se acomodando no espaço exíguo da sala de reuniões improvisada. De meninas púberes a mais maduras, na menopausa, o grupo se compõe quase exclusivamente de mulheres. Algumas amamentam no colo o filho pequeno, enquanto ouvem as explicações da enfermeira. As adolescentes formulam perguntas sugestivas de estarem iniciando a vida sexual, por vezes respondidas pelas mais experientes, com ensinamentos extraídos da vivência pessoal. Sob olhares de soslaio ante temas até então silenciados, observam-se demonstrações explícitas ou mais reservadas de solidariedade pactuada em torno de dificuldades expressas por aquelas que ousam revelar angústias íntimas. As paredes da sala em que se agrupam não asseguram vedação acústica para preservar a necessária privacidade, mas tal condição não parece preocupar as participantes. (Registros em diário de campo da reunião do grupo de Planejamento Familiar realizada no Centro de Saúde São José, em 19/06/2001).

A profusão de elementos acima levantada sugere bem a predominância de mulheres, fator essencial para a discussão do presente texto. Esse dado, detectado em pesquisa desenvolvida no Centro de Saúde São José (CSSJ), ocorre também nas demais unidades que integram o sistema municipal de saúde de Belo

\footnotetext{
* Mestre em Ciências Sociais pela PUC Minas. Docente da PUC-Minas.

\# Mestre em Filosofia pela UFMG. Doutor em Psicologia pela Universidade de Paris VII. Docente da PUC-Minas.
} 
Horizonte, especialmente nos serviços que atendem a populações de baixa renda, segundo estatísticas da Secretaria de Saúde desta cidade. Nesse contexto social, parece justificada a observação de Mascareño (citado por Castañeda, 2000) de que la salud tiene rostro de mujer. A pesquisa em questão focalizou a estrutura dos processos de informação desenvolvidos nos grupos de planejamento familiar implementados pela Prefeitura de Belo Horizonte.

O presente texto é resultado dessa pesquisa. Os procedimentos metodológicos escolhidos para $\mathrm{o}$ levantamento de dados foram inicialmente inspirados no modelo da pesquisa participante, o que determinou a opção pela presença da pesquisadora nas sessões de grupo realizadas no CSSJ. Tais grupos eram orientados por uma enfermeira encarregada da transmissão de informações e das discussões relativas aos diversos métodos contraceptivos. Num segundo momento, foram realizadas entrevistas semiestruturadas, no espaço da unidade de saúde, com 14 mulheres de um total de 30 participantes dos grupos observados - a presença masculina neles era praticamente nula - e com os cinco profissionais da equipe encarregada da implementação do Programa na unidade, a saber, o ginecologista, três enfermeiras e a gerente. A análise dos dados foi qualitativa, em função da perspectiva psicossociológica da pesquisa. Dados complementares foram ainda levantados, através de pesquisa documental, nos órgãos municipais de gestão e de controle social do programa, com o propósito de se conhecerem as referências normativas, conceituais e jurídicas do Programa de Planejamento Familiar, além de dados estatísticos relativos à situação socioeconômica, escolaridade e incidência de gravidez na população usuária desta e das demais unidades de saúde do distrito sanitário ao qual elas pertenciam.

A título de esclarecimento, observamos que o Centro de Saúde São José presta serviços básicos de atendimento à população da favela homônima, composta de aproximadamente 10 mil habitantes, que vivem em condições de extrema pobreza e dependem de recursos públicos para resolver problemas de saúde e efetivar os direitos reprodutivos. De acordo com dados do IPEAD (1998), essa população é predominantemente jovem e os índices de escolaridade são baixos: $54 \%$ s se situam abaixo de 21 anos, e, no total da população cadastrada, $74 \%$ têm apenas o primeiro grau incompleto. Em razão da precariedade das condições de vida e urbanísticas, a "Vila", como a região é designada pelos moradores, se enquadra nos espaços urbanos tipificados por Damatta (1997, p. 45) como "transitórios e problemáticos, que recebem tratamento diferente, que materializam a desigualdade e o conflito social, antinomia do desenvolvimento e da civilidade".

No aspecto de saúde reprodutiva, alguns dados da população usuária deste Centro de Saúde revelam a dimensão de seus problemas. Segundo levantamento do Distrito Sanitário Noroeste/PBH-DISANO, relativo a 1996, os índices de gestantes atendidas no CSSJ, com idade inferior a 20 anos e baixa ou nenhuma escolaridade, eram superiores à média das outras quinze unidades de saúde deste distrito sanitário. Assim, do total de 930 mulheres gestantes com menos de 20 anos atendidas no DISANO, 125 eram usuárias do "São José". Destas, a quase-totalidade era constituída de analfabetas ou com primeiro grau incompleto. Em razão disso, os altos índices de gravidez na adolescência constituíam um problema à parte para os profissionais do CSSJ e para outras instâncias da gestão municipal.

A precariedade das condições de vida da população motivou a inclusão do Centro de Saúde São José entre as Unidades de Saúde pioneiras na implantação do Programa de Planejamento Familiar (PPF) da Prefeitura de Belo Horizonte, em 1994. Por essa razão, escolheu-se o CSSJ como campo de pesquisa, observando-se que ele se assemelhava às demais unidades de saúde pública, na estrutura operacional e nas características socioeconômicas da população usuária. A investigação confirmou os desafios inerentes aos estudos desenvolvidos em contextos sociais de acentuada miséria. Ela exigiu novos exercícios de percepção, frente à condição da população usuária, além de estratégias específicas de comunicação, como uma interação mais informal com as mulheres entrevistadas, além de um esforço de interpretação de seus códigos lingüísticos, de seus valores e modos de vida. Assim é que, algumas vezes, o fio elucidativo dos dados se escondia no avesso da "casca empírica", como diria Demo (1995), encapsulando-se em situações inusitadas ou aparentemente casuais. E foi por vias tortuosas que emergiram dados relevantes para a nossa análise, ora nas falas, ora nos silêncios ou gestos contidos das mulheres, exigindo sensibilidade apurada para serem decodificados. A predominância feminina nos grupos pesquisados demandou também uma abordagem de gênero que ultrapassasse a conotação biologizante e determinista imputada a "sexo". Isso nos permitiu avaliar melhor a fragilidade das estratégias das unidades de saúde para a inclusão de homens no PPF.

Os dados aqui apresentados incluem os processos de inserção das mulheres nos grupos, bem como a opção pela contracepção, o acesso aos métodos contraceptivos, os conhecimentos acerca da anatomia 
e fisiologia da reprodução e dos efeitos do método adotado sobre o organismo. Eles revelam também os valores e modos de vida dessas mulheres, relacionados com: a reprodução e a contracepção; os conflitos entre casais; os papéis atribuídos a homens e mulheres; a organização e o funcionamento do PPF e do sistema público de saúde. Eles nos possibilitaram ainda analisar em que medida os direitos reprodutivos assegurados em lei se efetivam na prática.

Para contextualizar e historiar esses dados, vamos lembrar alguns aspectos sobre a conquista dos direitos reprodutivos no Brasil, donde brotou a formulação e a estruturação do Programa de Planejamento Familiar. Abordaremos, em seguida, as características da população atendida no Centro de Saúde São José.

\section{A CONQUISTA DOS DIREITOS REPRODUTIVOS E O PPF}

A proteção legal dos direitos reprodutivos no Brasil é fruto de um longo processo de luta em que contracenam diversos atores sociais. Por esta via, o planejamento familiar, até então dependente de iniciativas de governantes e entidades privadas, passou a constituir dever do Estado, como se lê no artigo 226, parágrafo 7 da Constituição:

Fundado nos princípios da dignidade da pessoa humana e da paternidade responsável, o planejamento familiar é livre decisão do casal, competindo ao Estado propiciar recursos educacionais e científicos para o exercício desse direito, vedada qualquer forma coercitiva por parte de instituições oficiais ou privadas (citado por Dora, 1999).

A universalidade dos direitos sexuais e reprodutivos se aplica indistintamente a homens e mulheres, estando expressa na Constituição e reiterada nos termos da Lei Federal 9.263, de dezembro de 1996, artigo $3^{\circ}$, que regulamenta a oferta de serviços de planejamento familiar:

O planejamento familiar é parte integrante do conjunto de ações de atenção à mulher, ao homem ou ao casal, dentro de uma visão de atendimento global e integral à saúde (grifos nossos).

No plano internacional, os documentos produzidos a partir das convenções multilaterais compõem a legislação de proteção aos direitos humanos, nos planos sexual e reprodutivo. Dentre os eventos de que o Brasil participou, merece destaque o Programa de Ação do Cairo (1994), que legitima a noção de direitos reprodutivos, como expresso no parágrafo 7.3 do documento final:

(...) os direitos de reprodução abrangem certos direitos humanos já reconhecidos em leis nacionais, em documentos internacionais sobre direitos humanos (...) Esses direitos se ancoram no reconhecimento do direito básico de todo casal e de todo indivíduo de decidir livre e responsavelmente sobre o número, o espaçamento e a oportunidade de ter filhos e de ter a informação e os meios de assim o fazer (...) (citado por Correa, 1998. p. 29).

No ano seguinte, o Brasil se fez representar na IV Conferência Mundial sobre a Mulher, em Beijing, na China. Entre os pontos acordados, constou uma referência (item 96) às relações homem-mulher:

As relações igualitárias entre a mulher e o homem, a respeito das relações sexuais e da reprodução, incluindo o pleno respeito à integridade pessoal, exigem o consentimento recíproco e a vontade de assumir conjuntamente a responsabilidade $\mathrm{e}$ as conseqüências do comportamento sexual (citado por Dora, 1999, p.78).

Segue-se um longo processo de luta, do qual participaram os movimentos de mulheres, além de grupos políticos e a Igreja Católica, dentre outros, até se chegar à proteção legal do direito de ter ou não filhos, quantos e quando, assegurado pela Constituição, além do acesso aos meios materiais e simbólicos para efetivá-lo. Não faltaram pressões sociais sobre as mudanças no comportamento reprodutivo: redução do número de filhos, novos papéis dos homens e mulheres, ligados à delimitação da prole, à sexualidade e à manutenção da família. Tal cenário já se configurava ao final dos anos 1960 e se tornou mais visível na década seguinte, no Brasil. Houve acentuada e generalizada queda da fecundidade, nos diversos estratos sociais, no meio rural e urbano, ressalvadas algumas flutuações regionais. A partir de então, as taxas de fecundidade vão gradualmente diminuindo, até alcançar, em tempos mais recentes, índices ainda mais baixos (2,7, em 1991, e 2,2 em 1999, segundo dados do Censo Demográfico).

\section{“DEUS DÁ, DEUS CRIA...””}

Sabemos que, em décadas anteriores, as decisões acerca de ter ou não ter filhos - mas isso ainda não desapareceu totalmente - eram afetas aos desígnios 
divinos e às regras da natureza. Por isso, no Brasil, não se registram demandas sociais e políticas de planejamento familiar capazes de balizar a discussão pública. Razões de ordem religiosa e econômica e valores culturais sustentavam a constituição de prole numerosa e as vantagens de ter filhos. A visão sexista dos papéis sociais, ainda não de todo superada, reservava à mulher uma posição de subordinação e de autonomia restrita, reduzindo-a a um corpo reprodutivo e cerceando, via de regra, ideais e projetos de vida que ultrapassem as funções de mãe e dona-decasa.

As mudanças no comportamento reprodutivo - a despeito das tentativas conservadoras de regulação, por parte da Igreja Católica - ocorreram de forma generalizada e à revelia de políticas de planejamento familiar, praticamente inexpressivas nas décadas de 1960 e 1970. Dentre as várias explicações desse complexo fenômeno, destaca-se a ampliação da mãode-obra feminina, na população economicamente ativa. Mas o trabalho assalariado, reduzindo a presença da mulher em casa, não a eximiu das funções domésticas tradicionais. Suas atribuições sociais acumuladas não foram partilhadas pelos homens nem amparadas por políticas de educação, como a guarda das crianças, o que tornou ainda mais difícil o cuidado de muitos filhos. O acúmulo de funções domésticas e profissionais ampliou o nível de autonomia da mulher, em suas decisões relativas à delimitação do número de filhos. Isso propiciou relações mais igualitárias, ou melhor, menos assimétricas, entre os casais.

Lembremos também o avanço farmacológico com a produção de anticoncepcionais. Isso foi significativo para o processo de "liberação da mulher", sendo o direito ao prazer sexual uma de suas bandeiras, possibilitando a separação entre reprodução e sexualidade. Nos anos 1960, métodos contraceptivos, como a pílula e o DIU (dispositivo intra-uterino), já se encontravam disponíveis no mercado. Neste processo, foi essencial o papel do movimento feminista, que ousou questionar valores, papéis e representações entranhados na cultura brasileira. Torna-se relevante o lugar das mulheres como ator político coletivo ou "na verdade, atrizes", no dizer de Souza Lobo (citado por Farah, 1999, p. 68), pois elas estavam presentes nos diversos movimentos sociais, não apenas na construção da cidadania reprodutiva. Isso abalou as matrizes culturais de subordinação da mulher, nos planos micro e macrossocial. Na visão de Citeli (1996, p.18), o cerne dessa transformação reside na desnaturalização dos processos que envolvem a reprodução, que, cada vez mais, deixa de ser representada como desígnio divino ou destino feminino inarredável, para ser pensada como fenômeno passível de controle e decisão individual.

Desnaturalizada, a reprodução torna-se passível de intervenção. Daí o aparecimento dos serviços de planejamento familiar, no Brasil, cuja efetivação se dá a partir de 1983, com a criação do PAISM (Programa de Assistência Integral à Saúde da Mulher). Este é considerado um marco na história das políticas de gênero no país, em função de seus princípios estruturadores, como a ênfase na dimensão educativa, "pretendendo-se alterar valores e práticas de saúde de caráter sexista", e a priorização de "ações de promoção da saúde das mulheres e não apenas da saúde de seus filhos" (Costa, citado por Costa \& Aquino, 2000, p.186). Todavia, a despeito da justeza dos princípios orientadores do PAISM, um ponto frágil de sua formulação é justamente a não-inclusão dos homens, particularmente nas ações relacionadas ao planejamento familiar.

A partir da Constituição de 1988, os serviços de planejamento familiar ofertados pelos municípios paulatinamente se ampliam; porém, só quase uma década depois foi promulgada a Lei Federal 9.263, de dezembro de 1996, que regulamenta a oferta de serviços. A referência para a normatização dos serviços é o manual "Assistência ao Planejamento Familiar" (Ministério da Saúde, 1996), que recomenda serem incorporados às ações de atendimento os valores e modos de vida da população:

\begin{abstract}
Os profissionais devem estar familiarizados com os mitos e percepções errôneas sobre os métodos anticoncepcionais (...) Deve-se combatê-los com sensibilidade, mas de maneira correta (Ministério da Saúde, 1996, p. 10. grifos nossos).
\end{abstract}

Sobre os termos grifados, cabe indagar: trata-se de "combater" sumariamente os mitos e preconceitos, ainda que "com sensibilidade", ou compreendê-los, conquanto estejam relacionados aos valores e modos de vida da população? A expressão "correta", que também destacamos, parecer conotar um juízo de valor, sem o correlato fundamento científico.

\section{A IMPLEMENTAÇÃO DO PPF E O FUNCIONAMENTO DOS GRUPOS NO CSSJ}

Os grupos de transmissão de informações constituem uma das ações do Programa de Planejamento Familiar implementado pela Prefeitura de Belo Horizonte. O Programa disponibiliza recursos técnicos e científicos para tratar os casos de 
esterilidade e para orientar as escolhas individuais de métodos contraceptivos: métodos naturais, condom ou "camisinha" masculina, diafragma, pílula hormonal, hormônio injetável de aplicação mensal e trimestral, dispositivo intra-uterino e cirurgias de esterilização. Implantado em 1994, para atender demandas da população usuária das unidades e dos profissionais de saúde, o Programa, hoje, se estende a todo o Sistema Municipal.

As referências da formulação do PPF são: no plano conceitual, o PAISM; no jurídico, a Constituição e a Lei Federal 9.263; no plano normativo, o manual "Assistência ao Planejamento familiar", do Ministério da Saúde, e os "Protocolos de Atenção à Saúde da Mulher", da Coordenadoria de Atenção à Saúde da Mulher, ligada à Secretaria Municipal de Saúde de BH. No conjunto destes documentos é reiterada a inclusão indistinta de homens e mulheres, explicitada na Constituição, embora sejam ambíguas as recomendações contidas nos dois últimos.

Veja-se, como exemplo, a recomendação acerca das atividades educativas que devem “(...) permear todas as atividades, possibilitando não só um maior diálogo entre o profissional de saúde e a mulher (...)" (Secretaria Municipal de Saúde/PBH, 2001, p.1, grifo nosso). Aqui, a ênfase recai exclusivamente na saúde da mulher, soando, pois, contraditória, em relação à proclamação da universalidade do atendimento.

Também nas normas elaboradas pelo Ministério da Saúde as ambigüidades se repetem, a despeito do princípio da paternidade responsável e do direito de livre escolha dos indivíduos e/ou casal. O referido manual recomenda que o treinamento de profissionais vise a “(...) prestar o atendimento ao indivíduo ou casal consoante ao enfoque da assistência integral à saúde da mulher..." (Ministério da Saúde, 1996, p. 13) (grifo nosso). E no que tange à consulta de orientação do método contraceptivo, que se segue à participação no grupo, determina o manual que se deva "(...) analisar a adequação da opção feita pela mulher (...)" (Ministério da Saúde, 1996, p. 26) (grifo nosso).

A participação na sessão de grupo que informa e auxilia na escolha individual do método contraceptivo é condição de acesso aos bens disponibilizados, segundo norma estabelecida pelo PPF. Após o grupo, a mulher (geralmente sem o parceiro) é encaminhada para a consulta ginecológica de disponibilização e orientação sobre o uso do método escolhido.

Entre os serviços de saúde reprodutiva oferecidos pelo CSSJ incluem-se consultas ginecológicas clínicas, encaminhamento para maternidades e hospitais de referência, acompanhamento pré-natal .
No entanto - e isso ocorre nas demais unidades do sistema municipal - os profissionais não recebem treinamento para a prestação dos serviços do PPF. No rol das especialidades médicas dessas unidades não há profissionais para tratar das questões reprodutivas específicas dos homens.

Quanto à distribuição de recursos para operar os métodos contraceptivos, verifica-se no CSSJ aquilo que é comum às demais unidades do sistema municipal: a insuficiência ocasional ou a nãodisponibilidade de alguns deles, particularmente de camisinhas, o que constitui motivo de queixa por parte da população, geralmente dirigida aos funcionários. ${ }^{1}$ Isso limita os critérios de escolha individual e da própria indicação médica.

A predominância de mulheres nos grupos, com demanda maciça pelos métodos contraceptivos, é verificada desde a implantação do PPF. E é também estrategicamente que elas se inscrevem neste programa: se o grupo lhes assegura a orientação do método contraceptivo, assegura também o acesso às consultas ginecológicas, independentes de tal orientação. No entanto, as vagas para as consultas são restritas, pois a unidade tem poucos profissionais para a população da "Vila", com suas demandas múltiplas. Isso mostra um dos pontos críticos do funcionamento do PPF e da estrutura da unidade.

\section{A OPÇÃO PELA CONTRACEPÇÃO E A ESCOLHA DO MÉTODO}

A predominância de mulheres nos grupos de planejamento familiar se repete nos demais serviços da unidade de saúde pesquisada. Algumas levam o filho para a consulta, outras acompanham a vizinha, marcando lugar na fila ou mesmo vendendo quinquilharias. Apesar de ficarem silenciosas perante os profissionais, durante as consultas, na sala de espera suas conversas são ruidosas e, por vezes, ouvem-se atritos e protestos contra os funcionários.

No grupo, as formas de participação são variáveis. Algumas mulheres, mais descontraídas, fazem perguntas e observações acerca da própria vida. Outras mantêm-se caladas. Por vezes, a linguagem se corporifica em gestos. Seja exemplo uma situação de vivência da intimidade entre os casais: ao final da reunião, uma adolescente apanhou de sobre a mesa a réplica de um pênis, usada para demonstrar o uso da camisinha. A iniciativa provocou, inicialmente, manifestações de reprovação nas colegas do grupo,

1 Numa sessão de grupo observada não havia camisinha disponível sequer para a demonstração do uso. 
todavia logo dissipadas com a afirmativa da coordenadora de que poderiam comparar a réplica à anatomia do parceiro. A partir de então, aquela "peça", tão familiar mas desconhecida, circulou de mão em mão, num ritual de exploração do órgão sexual masculino.

Se a presença dos homens é raríssima, tanto nos grupos quanto nas consultas de orientação sobre o método contraceptivo, sua ausência é apontada nas falas das participantes dos grupos, num misto de ironia e queixa. Elas justificam sua inserção nos grupos como forma de obter melhores esclarecimentos sobre a contracepção, pois suas escolhas do método muitas vezes se baseiam na própria experiência, nos conselhos de amigas, ou são decorrência de imposições do parceiro. Algumas escolhem a pílula entre os rótulos disponíveis na farmácia, optando pelas mais baratas, sem orientação médica, desprezando critérios de inocuidade e a confiabilidade do método.

Em resumo: as razões da escolha do método contraceptivo estão relacionadas aos valores e modos de vida da população, ao domínio precário de informações para operá-los, bem como à provisão dos recursos pelo sistema municipal de saúde. O DIU, a pílula hormonal, a camisinha masculina, e - com menor frequiência - o hormônio injetável, são os métodos preferidos das mulheres. À menção da vasectomia, cujos riscos cirúrgicos foram enfatizados como menores que a laqueadura de trompas, as participantes observaram que os homens a rejeitam pelo medo de "virar veado". A escolha da camisinha pela mulher, muitas vezes, está relacionada à prevenção da AIDS, já que a infidelidade é mencionada como típica da "natureza" do homem. Todavia, isso traz dificuldades de negociação com os parceiros, não só porque eles também podem desconfiar da fidelidade da mulher, mas principalmente pelo desconforto ou pela limitação do prazer. "Chupar bala com casca" e "comer banana sem descascar" seriam argumentos usados pelos homens, segundo as participantes dos grupos.

A preferência pelo DIU, por sua vez, é justificada pelas mulheres por não requerer conhecimentos para a operação e por não mobilizar conflitos entre o casal, conferindo à mulher maior "autonomia" no uso, já que, supostamente, dispensa negociação com o parceiro. Além do DIU, os métodos mais duradouros, como a pílula injetável e a cirurgia de esterilização, também são escolhidos por dispensarem procedimentos rotineiros de operação. "O médico põe lá e pronto, a gente não tem de se preocupar mais (...)" Algumas mulheres relataram temores relacionados a efeitos indesejáveis de tais métodos, o que não era suficiente para demover a preferência pelos mesmos.

Os conflitos com os parceiros, acima citados, têm relativo destaque entre os temas abordados pelas mulheres, quer de forma explícita - em falas que ganham a adesão das colegas - quer em confabulações solitárias. As queixas sobre imposições sexuais dos homens, a falta de diálogo ou a supremacia "das decisões deles" denotam a assimetria dos papéis e a subalternidade feminina. Tal condição foi claramente afirmada numa sessão em que a coordenadora, referindo-se às vantagens do DIU, enfatizou que o uso prescindia de negociação com o parceiro. Uma das participantes se contrapôs, enfaticamente: "mas eles é ignorante", numa referência ao autoritarismo dos parceiros. A coordenadora rebateu, destacando o direito da mulher de partilhar a decisão: "mas relação é de dois". Ao que a participante tornou a objetar: “(...) de dois, não, é de um só (...)", sugerindo o monopólio masculino nas decisões. Tal observação teve a concordância de outras mulheres. Muitas mencionaram, ora como queixa, ora com orgulho dissimulado, a alta frequiência de relações sexuais. Só uma minoria afirmou não se submeter a pressões do companheiro.

Se a fidelidade é exigida da mulher, para o homem o oposto é indicador de virilidade. E se a mulher não responde incondicionalmente à sua demanda, ele pode "procurar na rua". Conforme uma entrevistada, a solicitação da camisinha só ganha legitimidade, na ótica do parceiro, sob o argumento de que suas práticas sexuais "na rua" põem em risco a saúde da família. As mulheres são, pois, os agentes principais ou exclusivos da decisão sobre a adoção da contracepção, com a aquiescência apenas periférica dos parceiros. Mais que isso, só mesmo os imperativos econômicos e as precárias condições de vida pressionam por um consenso entre os casais, contrariando, para alguns, a aspiração por mais filhos.

De forma generalizada, as mulheres demonstram um precário conhecimento do próprio corpo, dos processos de ovulação, fecundação ou período fértil. A anatomia e a fisiologia da reprodução se restringem, para a maioria delas, ao reconhecimento da existência e função de algumas estruturas do aparelho reprodutor feminino, como o útero e, em menor grau, os ovários. Esse desconhecimento interfere fundamentalmente na vivência sexual, na escolha e uso dos métodos contraceptivos, na avaliação de sua inocuidade e efetividade, bem como de seus efeitos sobre o organismo. 


\section{SOBRE A PROVISÃO PÚBLICA DE MÉTODOS CONTRACEPTIVOS}

Entre os condicionantes da escolha do método, acima discutidos, devem-se mencionar também as precárias condições de provisão, pelo poder público, de recursos simbólicos e técnico-científicos. Os profissionais de saúde, nos grupos, levam em conta precariamente os valores e modos de vida da população, os papéis socialmente atribuídos a homens e mulheres. Sem formação e treinamento adequados, suas informações ou "aulas" costumam se restringir aos aspectos biológicos da reprodução e da contracepção, sem trabalhar seus mitos, equívocos ou valores. Ora, tais "aulas" supõem complexas questões técnicas e metodológicas, além da delicadeza de tratar os temas da sexualidade e do universo íntimo do casal.

Outra questão diz respeito aos procedimentos para a escolha do método contraceptivo em bases criteriosas e seguras. Vejamos alguns trechos do documento "Solicitação para contracepção cirúrgica", adotado no sistema municipal de saúde:

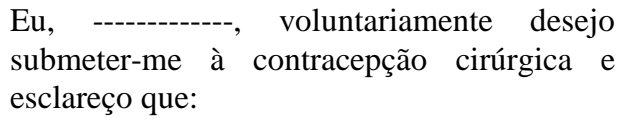

1-Tenho conhecimento sobre outros métodos contraceptivos que estão disponíveis neste Centro de Saúde, os quais me foram oferecidos (...)

5-Estou consciente que com a cirurgia estarei interrompendo minha fertilidade, que caso contrário poderia se prolongar por vários anos (o homem tem capacidade reprodutiva até a velhice (...) (Secretaria Municipal de Saúde/PBH, 2001)

Apesar de o documento afirmar que foram oferecidas, pelo poder público, todas as informações necessárias para a tomada de decisão "consciente" pela cirurgia contraceptiva, como vimos, elas são precariamente apropriadas nos grupos. Assim, os termos do formulário podem ser até constrangedores, na medida em que os demandantes devem confirmar conhecimentos que, na prática, raramente se comprovam.

Outro condicionante da escolha do método contraceptivo, já citado, é a irregularidade da provisão de recursos. Nesse caso, a indicação médica e a opção individual ficam sujeitas à disponibilidade de estoque. Além disso, entre a participação no grupo, a consulta ginecológica de orientação e o procedimento de aplicação do método, podem decorrer até quinze dias. Neste intervalo, as camisinhas disponibilizadas pela unidade de saúde são a única alternativa de contracepção.

Os dados acima relatados mostram, pois, que muitas mulheres utilizam métodos contraceptivos que não correspondem a uma escolha pessoal. Dados da Gerência de Epidemiologia e Informação da Secretaria Municipal de Saúde, relativos a 2000, sobre a escolha dos métodos contraceptivos no CSSJ, revelam a prevalência da pílula (64\%) entre as mulheres que iniciavam a contracepção, seguida do método hormonal injetável $(29,9 \%)$, do DIU $(9,3 \%)$ e do condom (3\%). São nulos os índices de escolha dos métodos naturais e do diafragma. Ademais - deve-se ressaltar - os métodos hormonais injetáveis trimestralmente têm sido questionados pelas feministas, em razão de efeitos colaterais. Ante tais condições ou constrangimentos, a escolha de um método contraceptivo fica comprometida e impõe graves ônus para a saúde emocional e reprodutiva, ou para o relacionamento entre os casais. A desarticulação entre as atividades educativas e clínicas e as políticas de gênero expõe a precariedade da atenção à saúde reprodutiva.

\section{CONSIDERAÇÕES SOBRE OS RESULTADOS DA PESQUISA}

A complexidade dos fenômenos acima tratados, relativos à demanda pelo planejamento familiar, supõe múltiplas facetas éticas, religiosas, culturais, políticas, psicológicas e técnico-científicas, gerando acirradas polêmicas. Ao terminar nossa exposição, vamos focalizar duas questões que parecem centrais à nossa pesquisa: a primeira, relativa ao lugar político e socioafetivo da mulher, nos processos de contracepção; a segunda, relativa aos limites ou à inoperância do poder público, nos programas de planejamento familiar.

\section{Contracepção: autonomia feminina ou encargo?}

Vimos que a predominância de mulheres na demanda pelos grupos de planejamento familiar não garante que elas sejam os agentes principais ou exclusivos da escolha do método contraceptivo, com o correlato grau de autonomia. Na verdade, achamo-nos aqui diante de um desafio interpretativo: de um lado, a subalternidade feminina deixa ao homem as decisões relativas à vida sexual (o universo pesquisado está marcado pelo androcentrismo, sendo a virilidade tomada aqui como dominação e violência - o elemento identitário da masculinidade). Por outro lado, se é a mulher que demanda os métodos contraceptivos, cabe- 
lhe um quantum significativo de decisão, relativamente à delimitação da prole ou à prevenção da gravidez não desejada. Daí a questão: seria isso devido apenas aos fardos da concepção, do cuidado e da educação dos filhos? A resposta não é simples, se pensarmos que, em passado relativamente recente, a mulher pouco ou nada decidia sobre a limitação dos filhos. Poderíamos falar, então, de uma dialética submissão-decisão ou subalternidade-autonomia?

O desafio analítico continua: se a autonomia não parece presente na vida das mulheres da "Vila", ao mesmo tempo, sua submissão não é incondicional. Nos grupos apareceram o inconformismo e as narrativas de enfrentamento dos parceiros. Tal postura, aliás, era corroborada por sinais definidos de auto-estima: mulheres trajavam roupas simples, porém coloridas e bem-cuidadas, algumas moldando as curvas com sensualidade, rindo alto, relatando estratégias de drible da tirania dos parceiros; outras, mesmo em silêncio, sinalizavam pelo olhar, pelo riso contido e outras expressões do corpo, que se identificavam com as falas mais ousadas que denunciavam a submissão feminina. Não vemos, pois, alternativas excludentes (subalternidade-autonomia, por exemplo), pois as duas se entrelaçam. A predominância feminina nos grupos aponta para traços ambíguos de autonomia e de encargo. Enfim, se a decisão do planejamento familiar é teoricamente partilhada pelo casal, são as mulheres que dominam, embora precariamente, as informações acerca da fisiologia e da anatomia da reprodução, da confiabilidade ou da inocuidade dos métodos contraceptivos, do monitoramento de seus efeitos colaterais.

Cabe aqui uma observação complementar: se a opção de limitar o número de filhos é do casal, ela seria anterior à escolha do método contraceptivo. De fato, várias mulheres se declararam responsáveis pela decisão, com o acordo do companheiro, devido principalmente à falta de condições econômicas e sociais para criar os filhos dignamente. Nesse caso, a contracepção seria mais uma contingência do que propriamente uma opção, que reverbera no universo íntimo e nos projetos de vida do casal.

\section{Os limites ou a inoperância do poder público}

$\mathrm{Se}$ as mudanças nos papéis "masculino" e "feminino" não se fazem sem conflitos, nos planos intra-subjetivo e intergêneros, as instituições de saúde parecem simplesmente indiferentes a elas, não modificando a estrutura de alguns serviços inadequados para homens e mulheres. Assim, a ausência dos homens, nos grupos do PPF, embora vinculada a papéis sociais que os tornam refratários a tal participação, pode estar relacionada, por exemplo, ao horário das sessões, na unidade de saúde pesquisada: 9:00h e 14:00h - períodos inadequados para trabalhadores que cumprem jornada fixa.

Não obstante a apartação dos homens não é específica do CSSJ. Como observa Siqueira (1999), há uma tendência comum, em instituições de saúde, a eleger as mulheres como o alvo principal das ações. Assim, certas representações do que é ser masculino e feminino incorporam-se às práticas das instituições sociais, que podem ser consideradas "generificadas", em termos de formação, socialização e reconhecimento dos sujeitos. Segundo Costa (2001), na implementação de políticas de saúde, é comum a vigência da concepção biologizante, que desconhece tal faceta social.

A mulher é ainda vista na tradicional função de "cuidadora", restando ao homem, quando muito, o papel de coadjuvante, como observa Siqueira (1999). Todavia, as mulheres não são apenas "mães" e "donas-de-casa". $\mathrm{Na}$ população pesquisada, porcentagem significativa delas divide com os homens os encargos de provisão das famílias. Voltamos, assim, à questão do encargo feminino, dadas as diversas pressões que sofre a mulher. Sabemos que no caso dos filhos "não planejados", devido a falhas nos métodos contraceptivos, ela deve arcar com a responsabilidade de criar e educar. Some-se a isso a inexistência de creches públicas, o que onera e limita ainda mais, principalmente as mães, nos seus múltiplos "novos papéis" acima mencionados.

As situações mencionadas sugerem, pois, que o PPF não está cumprindo com a eficácia desejada os objetivos que justificaram a sua implantação e funcionamento. Trata-se de uma situação particular ou anômala da unidade de saúde estudada? Julgamos que não. Os problemas aqui apontados são frequientes, de um modo geral, no sistema municipal de saúde, o que é incompatível com as "razões" centrais da criação do Programa. Com a devida precaução para não cairmos em generalizações indevidas, julgamos que as lacunas na implementação do PPF podem ser extrapoladas para o sistema público de saúde, em geral, o que remete à forma como, historicamente, vem se arquitetando a precária e ambígua cidadania reprodutiva, no Brasil.

Nessa direção, a pesquisa ainda mostrou que, se a escolha do método contraceptivo é uma iniciativa geralmente feminina, sem o suporte adequado do Estado, as mulheres pobres se valem de iniciativas próprias para evitar a gravidez indesejada, arcando com o ônus financeiro e os danos para a própria 
saúde, recorrendo ao aborto ou adquirindo a pílula na farmácia, sem orientação adequada. Tais alternativas constituem a face mais perversa do acesso aos recursos para a limitação da prole e atentam contra os direitos reprodutivos assegurados pela Constituição. O cerne da estrutura da cidadania no Brasil, arquitetada nos anos 1930, teria como princípio conceder controlando e incluir restringindo. Esse princípio perverso continua incrustado na história política do país. As "fraturas da cidadania", denunciadas pelo movimento sanitário, na década de 1980, apareciam na oferta de programas direcionados à população mais pobre, pelo Ministério da Saúde, ao lado de melhores serviços ofertados pelo INAMPS à classe média e aos trabalhadores do setor formal. Vemos aí a lógica da "cidadania regulada"2 instaurada no período Vargas. Em tempos mais recentes, a despeito do universalismo formal do direito à saúde, a exclusão opera por dentro das instituições de atendimento e gestão, através de incongruências nas práticas de saúde, das representações pejorativas sobre a população pobre atendida $^{3}$, da negação ou desconsideração de seus valores e modos de vida. Telles (1999) argumenta que a concessão de direitos, no Brasil, se sustenta por uma "lógica de contrários": o que se constrói em direito formal se desmancha na execução, o que se proclama em discurso não se efetiva na prática. Os direitos reprodutivos não escapam à lógica em que se pauta a cidadania no Brasil, a despeito dos avanços nos critérios de inclusão formalizados em lei.

A implantação do SUS (Sistema Único de Saúde) criou, institucionalmente, as condições para o acesso e a efetivação dos direitos reprodutivos. O Programa de Planejamento Familiar foi formulado e implementado pela Prefeitura de Belo Horizonte, anos mais tarde, com tal propósito. No entanto, como observa Citeli (1996), na lógica que conforma historicamente a cidadania no Brasil, tais condições não asseguram, por si, a efetivação:

O fracasso das políticas públicas voltadas para a saúde reprodutiva, em geral, e para a anticoncepção em particular, (...) não pode ser obscurecido, pois as brasileiras ainda

2 O conceito de "cidadania regulada" foi cunhado por Santos (1979) para explicar a lógica de constituição dos direitos sociais no período getulista.

3 Sabemos que, no jargão usado por profissionais das unidades públicas de saúde, o usuário anônimo do SUS é conhecido pela alcunha de "jacaré". continuam lidando com a reprodução em um cenário caracterizado (...) pelo uso irregular e desprovido de assistência adequada de anticoncepcionais orais, pelo recurso exagerado à esterilização e ao aborto clandestino, pela baixa disponibilidade de métodos anticoncepcionais nos serviços públicos, ao lado das taxas de mortalidade materna. (Citeli, 1996, p. 5).

Pode-se aventar que a exclusão, inerente às condições de funcionamento dos grupos e do PPF, reitera a subalternidade social, repercutindo na subjetividade individual e coletiva. Para além da polissemia do termo exclusão, nós o tomamos aqui num sentido específico, definido no Mapa da Exclusão Social de Belo Horizonte como “(...)p rocesso que impossibilita parte da população de partilhar dos bens e recursos oferecidos pela sociedade, conduzindo à privação, ao abandono e à expulsão desta população dos espaços sociais." (Secretaria Municipal de Planejamento, 2000, p. 5).

Os reflexos subjetivos dessa impossibilidade de partilhar os espaços, os bens e os recursos sociais, remetem diretamente à noção de sofrimento que Ricoeur (1994) define como impotência para falar e para agir (impuissance à dire et impuissance à faire). De fato, a face explícita de tal impotência está não apenas na condição socioeconômica dos usuários ou na precariedade de recursos materiais e de informação para a prática dos métodos contraceptivos, mas talvez e principalmente no próprio desconhecimento de seus direitos reprodutivos.

\section{REFERÊNCIAS}

Castañeda, M. H. (2000). Participación, empoderamiento y control social em salud. Em A. M. Costa, E. MerchánHamann \& D. Tajer (Orgs), Saúde, eqüidade e gênero: um desafio para as políticas públicas (pp.243-259). Brasília: Editora Universidade de Brasília.

Citeli, M. T. (1996). Saúde reprodutiva e anticoncepção no Brasil pós-60. Em 50 Programa de Estudos em Saúde Reprodutiva e Sexualidade - Módulo III: Concepção e anticoncepção, (pp.1-24). Campinas: Unicamp/ Nepo.

Correa, S. (1998). Anticoncepcionais injetáveis na perspectiva feminista: o debate histórico e os novos desafios. Em M. Arrilha \& M. T. Citeli (Orgs.), Políticas, mercado, ética: demandas e desafios no campo da saúde reprodutiva (pp.25-41). São Paulo: Editora 34.

Costa, A. M. \& Aquino, E. L. (2000). Saúde da mulher na reforma sanitária brasileira. Em A. M. Costa, E. MerchánHamann \& D. Tajer (Orgs), Saúde, eqüidade e gênero: um desafio para as políticas públicas (pp.181-202). Brasília: Editora Universidade de Brasília. 
Costa, S. G. (2001). Saúde, gênero e representações sociais. Em R. M. Muraro \& A. B. Puppin (Orgs.), Mulher, Gênero e Sociedade (pp.112-123). Rio de Janeiro: Relume Dumará. Damatta, R. (1997). Casa, rua e outro mundo: o caso do Brasil. Em R. Damatta. A casa e a rua. Rio de Janeiro: Rocco.

Demo, P. (1995). Metodologia científica em Ciências Sociais. São Paulo: Atlas.

Dora, D. D. (1998). Direitos sexuais, direitos reprodutivos e direitos humanos: conceitos em movimento. Em M. Arrilha \&. M. T. Citeli (Orgs.), Políticas, mercado, ética: demandas e desafios no campo da saúde reprodutiva (pp.69-80). São Paulo: Editora 34.

Farah, M F. S. (1999). Gênero e políticas públicas na esfera local de governo. Organização e Sociedade, 6(14), 65-104.

IPEAD-UFMG. (1998). Levantamento do perfil sócioeconômico dos residentes permanentes da Vila São José e das características construtivas de seus domicílios. (Mimeo).

Ministério da Saúde. (1996). Assistência ao Planejamento Familiar. Brasília: Secretaria executiva de Coordenação de Saúde da Mulher.
Ricoeur, P. (1994). La souffrance n'est pas la douleur. Autrement. Série Mutations: Souffrances - corps et âme, épreuves partagées. (pp.58-69) Paris: Autrement.

Santos, W. G. (1979). Cidadania e Justiça. Rio de Janeiro: Campus.

Secretaria Municipal de Planejamento/PBH. (2001). Protocolos de atenção à saúde de mulher, 1(4).

Secretaria Municipal de Planejamento/PBH. (2000). Planejar BH - Mapa da exclusão social de Belo Horizonte, 2(8).

Siqueira, J. T. (1999). Novas formas de paternidade: repensando a função paterna à luz das práticas sociais. Em A. Silva, M. C. Lago \& T. R. A. Ramos. (Orgs.), Falas de gênero - teorias, análises, leituras (pp.187-200). Florianópolis: Editora Mulheres.

Telles, V. S. (1999). Direitos sociais - afinal do que se trata? Belo Horizonte: Editora UFMG.

Recebido em 23/06/2004

Aceito em 24/09/2004
Endereço para correspondência:
Maria Helena Camargos Moreira: Departamento de Psicologia. Av. Dom José Gaspar, 500. Belo Horizonte, MG. CEP: 30535-610. E-mail: mahecam@uol.com.br 